\title{
Pathogenicity of some entomopathogenic fungal strains to green peach aphid, Myzus persicae Sulzer (Homoptera: Aphididae)
}

\author{
Khadija Javed ${ }^{1}$, Humayun Javed ${ }^{2}$, Tariq Mukhtar ${ }^{3}$ and Dewen Qiu ${ }^{1 *}$
}

\begin{abstract}
Pathogenicity of four fungal strains, two of Beauveria bassiana (designated as BB-72 and BB-252), and two of Lecanicillium lecanii (designated as V-4 and CS-625) to green peach aphid, Myzus persicae Sulzer (Homoptera: Aphididae) was assessed. All treatments showed highly significant effects on the mortality of the aphid when applied as filtrate or conidia. The application methods did not have a significant effect on the mortality rate. The overall mortalities caused by both applications were statistically similar. The maximum overall mortality was caused by BB-72, followed by CS-625 in both application methods. On the other hand, (V-4) caused the minimum mortality rate, followed by (BB-252), which was statistically similar to those caused by $\mathrm{V}-4$. The time also had significant effects on aphid mortality rates. The mortality was the minimum after 3 days reaching its maximum after 10 days. As the number of days increased, there was a corresponding increase in the mortality showing a direct relationship between mortality and time. The maximum mean individual mortality of 95\% was caused by CS-625, followed by BB-72 (92\%) after 10 days with the conidial application. Similarly, the combined effects of the three most virulent fungal strains showed highly significant differences on the mortality of peach aphid. The combination BB-72 + BB252 showed the highest percent mortality, followed by BB-72 + BB-252 + CS-625. The combinations BB-72 + CS-625 and BB-252 + CS-625 had statistically similar effects of causing aphid mortality.
\end{abstract}

Keywords: Green peach aphid, Entomopathogenic fungal strains, Pathogenicity, biocontrol, Mortality

\section{Background}

Aphids are important pests of many vegetables and fruits as they suck the sap of plants that is followed by the development of sooty mold on damaged plants (Tang et al. 2017). Among the most damaging and common species of aphids are the green peach aphid, Myzus persicae Sulzer; the cabbage aphid, Brevicoryne brassicae L.; the potato aphid, Macrosiphum euphorbiae Thomas; and the melon (or cotton) aphid, Aphis gossypii Glover (Homoptera: Aphididae). Aphids are serious pests as they are known to disseminate the viruses among healthy plants. Peach and apple orchards are intensively treated by insecticides for managing the insect pests. Aphids have developed resistance against commonly used pesticides

\footnotetext{
* Correspondence: qiudewen@caas.cn

'The State Key Laboratory for Bio-Pesticides Engineering of Plant Disease Biocontrol and Insect Pests, Institute of Plant Protection, Chinese Academy of Agricultural Science, No. 12 Zhong-Guan-Cun South Street, Beijing 100081, China

Full list of author information is available at the end of the article
}

(Rousselin et al. 2017). There are more than 700 fungus and nematode species which attack insect pests (Ak 2019; El Husseini 2019a; Javed et al. 2019; Tuncer et al. 2019). The commonly used strains having potential for pest management have been categorized into two groups. One group includes Hyphomycetes in Deuteromycotina and the other belongs to Entomophthorales in Zygomycotina (Feng 1998). Very few entomopathogenic fungi (EPFs), viz. Nomuraea rileyi, Beauveria bassiana, Paecilomyces fumosoroseus, Metarhizium anisopliae, B. brongniartii, and Lecanicillium lecanii, have been registered as products to control insect pests (Shah and Goettel 1999). B. bassiana and L. lecanii, the two wellknown EPFs, have many strains that cause white muscadine disease to a number of insect families and species including aphids. The spores of these EPFs simply need to be in contact with target hosts and rapidly control the insect ultimately. Upon controlling of insects, the produced white molds have more infective spores spreading 
to the healthy pest populations. Aphids in greenhouses and hydroponic systems cannot be treated with insecticides because of released pollinators and other biocontrol agents (Dunne and Donovan 1977) and there are numbers of EPFs which have great potentials for controlling aphids' populations and can be included successfully in biological control programs (Nielsen and Wraight 2009).

B. bassiana and L. lecanii are the most studied EPFs and well known as virulent biocontrol agents of a wide range of forest, field crops, and greenhouse pests. These EPFs are equally effective in desert, agricultural, and forest habitats (Dhar et al. 2019; El Husseini 2019b; Sayed et al. 2019). The strains of both EPFs can be easily isolated from the infected soil-dwelling pests or from vegetation pests (Freed et al. 2011).

The use of biological control agents, either alone or integrated with other pest management strategies, is one of the alternatives to chemical insecticides (Singh et al. 2012). In the biological control, many antagonists have shown efficacy against insect pests. Among these, the fungi B. bassiana and L. lecanii are ubiquitous in distribution and have the potential to control aphids successfully. The objective of the present study was to evaluate the pathogenicity of two antagonists for the management of green peach aphid, M. persicae, under laboratory conditions.

\section{Materials and methods Insect culture}

M. persicae was collected from cabbage fields and shifted to Chinese cabbage already potted under insect net maintained at $24^{\circ} \mathrm{C}, \mathrm{R} . \mathrm{H}$. of $45-60 \%$, and $16: 8$ (light to dark) photoperiod in the laboratory (Khan et al. 2012). The plants were replaced weekly to provide enough nutrition for reared insects.

\section{Fungal isolates}

Four fungal isolates, including two strains of $B$. bassiana and two of $L$. lecanii were evaluated for their pathogenicity against the aphid (Table 1). The fungal isolates were maintained on potato dextrose agar (PDA) slants in tubes at $4^{\circ} \mathrm{C}$. The isolates were grown and multiplied on the PDA at $25^{\circ} \mathrm{C}$ for 14 days and stored at $4{ }^{\circ} \mathrm{C}$ (Javed et al. 2019).

\section{Preparation of filtrates and conidial suspensions of fungal isolates}

Conidial suspensions of the tested fungal isolates were prepared by harvesting conidia from culture plates of each fungal isolate on the 20th day of culturing in $0.02 \%$ Tween solution. The suspensions were vigorously stirred and filtered through a sterile cheese cloth. The conidia in suspensions were counted with the help of a hemocytometer under a microscope and finally adjusted to $10^{7}$ conidia per milliliter. The viability of conidia was confirmed, following the method described by HywellJones and Gillespie (1990).

The culture filtrates of isolates of the tested EPFs were prepared according to the method of Khan et al. (2012). Four milliliters of the conidial suspensions from each isolate were poured separately into $100 \mathrm{ml}$ of Adamek's liquid medium and incubated for 3 days in a shaking incubator at $150 \mathrm{rpm}$. For the preparation of $1 \%$ secondary culture filtrate, $2.5 \mathrm{ml}$ of primary culture filtrate was mixed by $250 \mathrm{ml}$ of Adamek's liquid medium and incubated for 6 days at $26^{\circ} \mathrm{C}$ in a shaking incubator at 150 rpm. The solution was filtered, centrifuged at 10,000 rpm at $4{ }^{\circ} \mathrm{C}$ for $30 \mathrm{~min}$, and again filtered through $0.45 \mu \mathrm{m}$ pore size Millipore membrane filter.

\section{Pathogenicity bioassays}

In the first experiment, the virulence of tested fungal isolates was assessed individually against the green peach aphid, using their filtrates and conidial suspensions. Bioassays were performed, using a leaf dip method, following the procedures described by $\mathrm{Xu}$ et al. (2002). Leaves from cabbage plants were collected and cut into leaf disks of $50 \mathrm{~mm}$ diameter. Leaf disks were separately soaked into the filtrates and conidial suspensions of each fungal isolate. After treatment, the leaf disks were placed on a sterilized filter paper for $30 \mathrm{~min}$ to absorb the suspension. The cabbage leaves were transferred to $6 \mathrm{~cm}$ Petri dishes containing a piece of damp filter paper. For control, leaf disks were only dipped in $0.05 \%$ Tween 80 solution for the same time duration. Ten green peach aphids were released in each Petri dish with the help of a camel hairbrush. All the Petri dishes were kept at $26 \pm$ $2{ }^{\circ} \mathrm{C}$ with a light-to-dark ratio of $16: 8 \mathrm{~h}$, respectively. The mortality rate was recorded daily up to the 10th day.

In the second experiment, three isolates showing the maximum mortality rates in single bioassays (BB-72, BB-

Table 1 Detail of entomopathogenic fungi used in the study

\begin{tabular}{lllll}
\hline Sr. No & Entomopathogenic fungi & Isolate code & Source & Geographical area \\
\hline 1 & Beauveria bassiana & BB-72 & Green peach aphid & Vladivostok (Russia) \\
2 & B. bassiana & BB-252 & Green peach aphid & Vladivostok (Russia) \\
3 & Lecanicillium lecanii & V-4 & Whitefly & Moscow (Russia) \\
4 & L. lecanii & CS-625 & Green peach aphid & Suwn (Korea) \\
\hline
\end{tabular}


252, and CS-625) were tested again but in combinations. The treatments were as follows:

$$
\begin{aligned}
& \mathrm{T} 1=\mathrm{BB}-72+\mathrm{BB}-252 \\
& \mathrm{~T} 2=\mathrm{BB}-72+\mathrm{CS}-625 \\
& \mathrm{~T} 3=\mathrm{BB}-252+\mathrm{CS}-625 \\
& \mathrm{~T} 4=\mathrm{BB}-72+\mathrm{BB}-252+\mathrm{CS}-625 \\
& \mathrm{~T} 5=\text { Tween } 80
\end{aligned}
$$$$
\text { T6 = Water }
$$

Dead aphids were counted and placed into a dark room for 10 days to confirm mortality by the pathogens. After confirmation, only those aphids were counted on which pathogen growth appeared. Mortality was observed on a daily basis, and percentages were calculated after the 3rd, 6th, and 10th day of treatment. The percent mortality in each treatment was calculated and corrected by Abbott's formula (Abbott 1925) as follows:

$$
\text { Mortality }(\%)=\frac{t-c}{\mathrm{c}} \times 100
$$

where $t$ is the percent mortality in the treatments by fungal isolates and $c$ is the percent mortality in the control.

\section{Statistical analysis}

All the treatments were repeated four times. The corrected aphid mortality rate was analyzed by using two-way factorial analysis of variance (ANOVA), using Statistix (8.1) software. Comparisons of treatment means were performed, using Fischer's protected least significant difference (LSD) test at $P=0.05$.

\section{Results and discussion}

Pathogenic potential of fungal strains against $M$. persicae The analysis of variance showed highly significant effects of the biocontrol treatments $(F=122.62$; df $=5$,
105; $P<0.001)$ on the mortality of the peach aphid, when applied as filtrate or conidia. However, there was an insignificant effect on the mortality rates between the application methods $(F=2.24 ; \mathrm{df}=1,105$; $P=0.138)$. The mortality rates caused by conidial treatment were slightly higher (Fig. 1). The maximum overall mortality rate (54.17 and $52.5 \%)$ was caused by $B$. bassiana (BB-72), followed by L. lecanii (CS-625) showing 50.83 and $47.55 \%$ mortalities for both application methods. On the other hand, L. lecanii (V-4) caused the minimum mortality rate (40 and $39.17 \%$ ), followed by $B$. bassiana (BB-252) which gave 41.67 and $39.17 \%$ mortality rates. They were statistically similar to those caused by V4 as shown in Fig. 2. The duration also had significant effects $(F=452.73$; df $=2,105 ; P<0.001)$ on aphid mortality. The mortalities were found to be the minimum after 3 days and reached the maximum after 10 days. A direct correlation was observed between mortality and time. As the number of days increased, there was a corresponding increase in mortality. These relationships are shown by trend lines and regression equations in Fig. 3. The interaction between duration and treatments was found highly significant $(F=39.90$; $\mathrm{df}=10,105 ; P<0.001)$ and that between application methods and duration was also significant $(F=4.44 ; \mathrm{df}=2,105 ; P=0.014)$. Contrarily, the interactions between application methods and treatments $(F=0.31 ; \mathrm{df}=5,105 ; P=0.908)$ and that between application methods, duration, and treatments were insignificant $(F=0.4 ; \mathrm{df}=10,105 ; P=0.943)$. The maximum mean individual mortality of $95 \%$ was caused by CS- 625 , followed by BB-72 (92\%) after 10 days at conidial application. The individual mortalities by each biocontrol agent with both application methods at three time intervals are given in Table 2.

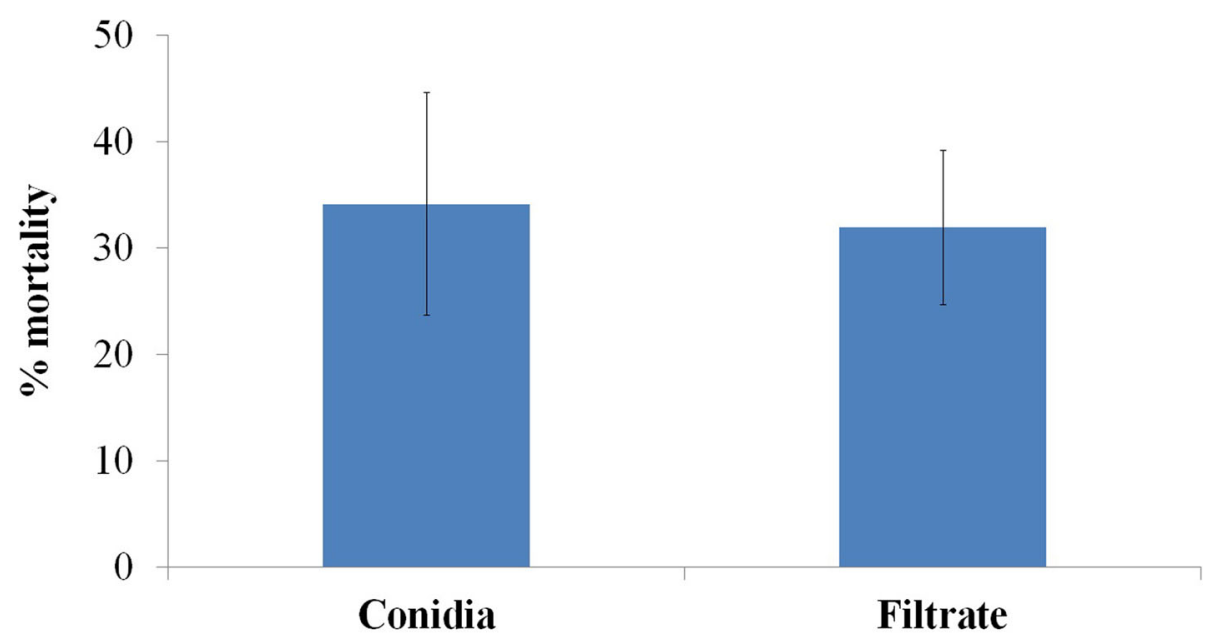

Application method

Fig. 1 Overall effect of conidial and filtrate application of fungal isolates on Myzus persicae mortality 


\section{Conidia $=$ Filtrate - Linear (Conidia) - Linear (Filtrate)}

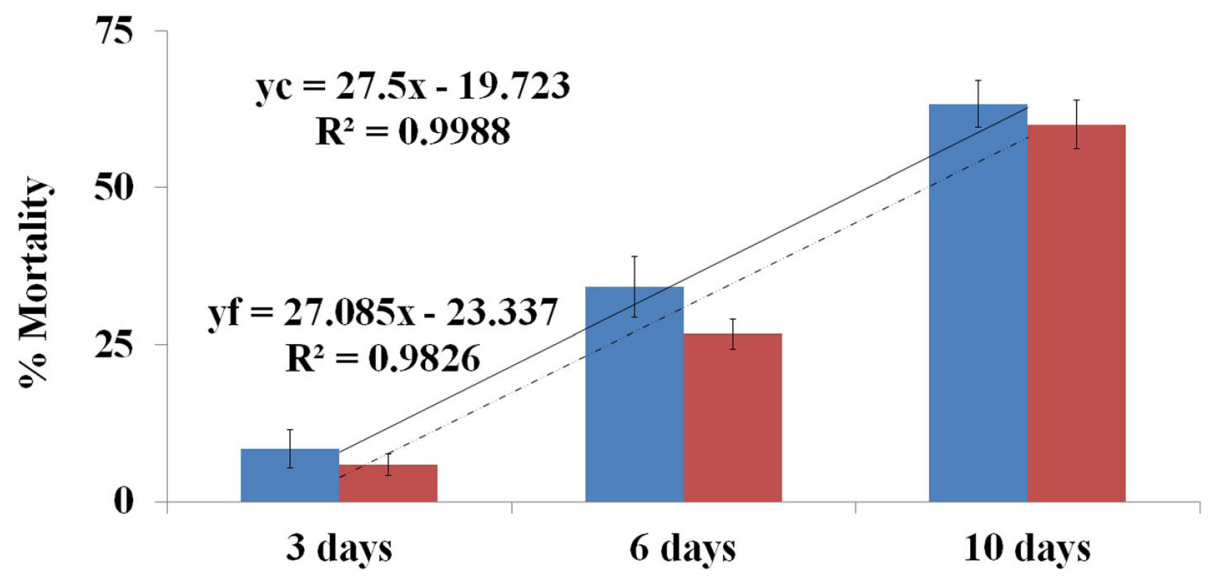

Fig. 2 Overall effect of conidial and filtrate application of fungal isolates on Myzus persicae mortality after three time durations

Pathogenicity of combined conidial suspensions of fungal strains against $M$. persicae

The analysis of variance regarding combined effects of three virulent fungal strains $(F=73.66$; $\mathrm{df}=4,42 ; P<$ $0.001)$, duration $(F=279.83$; $\mathrm{df}=2,42 ; P<0.001)$, and their interactions $(F=13.69 ; \mathrm{df}=8,42 ; P<0.001)$ showed highly significant effects on the mortality rates of peach aphid. The combination of BB-72 + BB-252 showed the highest percent mortality of $89.04 \%$, followed by BB-72 + BB-252 + CS-625 combination which caused $86.66 \%$ mortality. The combinations of BB-72 + CS-625 and BB-252 + CS-625 were statistically at par with each other's in causing aphid mortality as shown in Fig. 4. The individual mortality rate by each combination of fungal strains at three time intervals is given in Table 3.
In the present study, all the biocontrol agents caused mortality of green peach aphid with various degrees singly and in combinations and can be used effectively for the management of $M$. persicae. Fungal isolates are effective biological tools against many target pests of controlled and semi-controlled glass-houses without causing remarkable loss to other biocontrol agents and pollinators. Various studies have found entomopathogens as a strong tool of biological control of sucking insect pests (Amnuaykanjanasin et al. 2013; Yun et al. 2017; El Husseini 2019c; Mohamed 2019; Sain et al. 2019).

In the present study, the selected strains of EPFs were found effective to control the green peach aphid under laboratory conditions. The results are strengthened by the findings of previous studies that fungal strains of $B$. bassiana and L. lecanii effectively controlled $M$. persicae

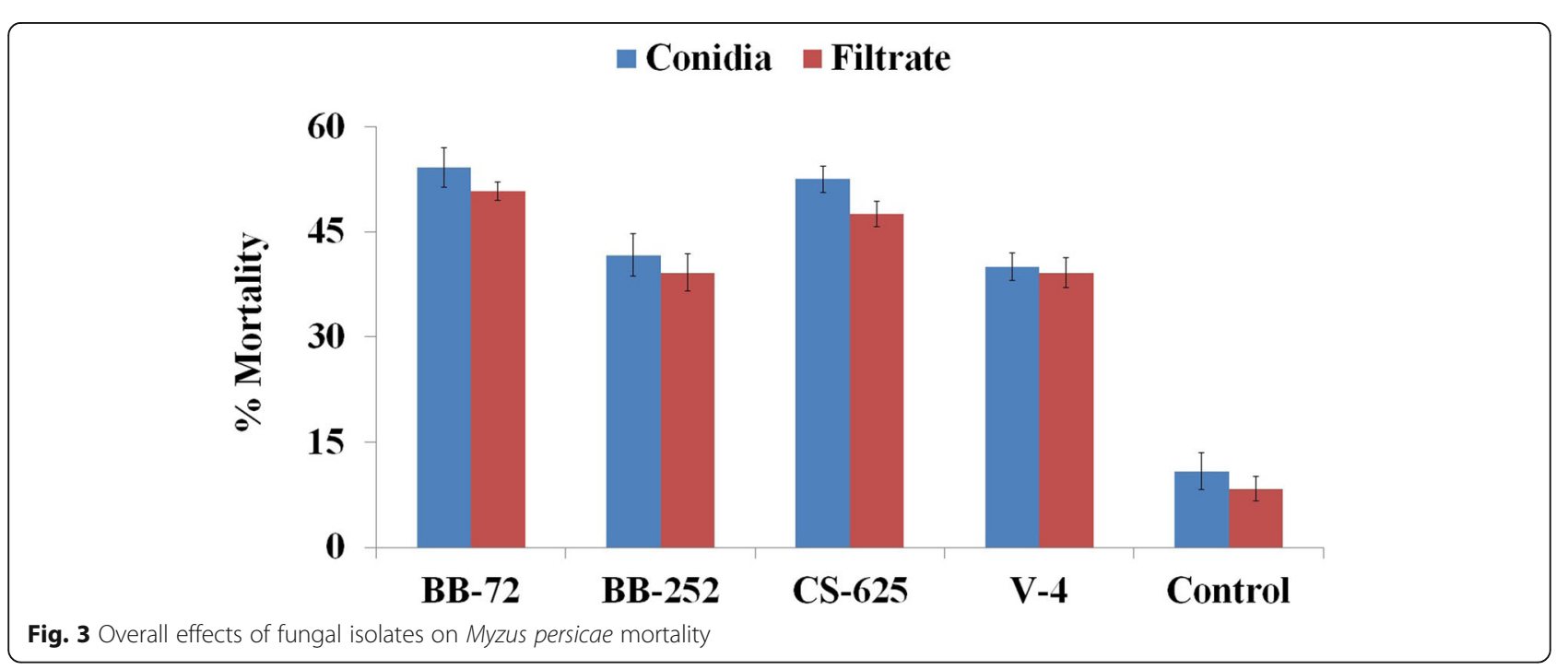


Table 2 Mortality of green peach aphid in conidial and filtrate applications

\begin{tabular}{|c|c|c|c|c|c|c|}
\hline \multirow[t]{3}{*}{ Treatments } & \multicolumn{6}{|c|}{$\%$ Mortality of green peach aphid in } \\
\hline & \multicolumn{3}{|c|}{ Conidial application after } & \multicolumn{3}{|c|}{ Filtrate application after } \\
\hline & 3 days & 6 days & 10 days & 3 days & 6 days & 10 days \\
\hline Beauveria bassiana, (BB-72) & $10.00 \mathrm{ab}$ & $50.00 \mathrm{fg}$ & $92.50 \mathrm{ij}$ & $15.00 \mathrm{abc}$ & $60.00 \mathrm{~g}$ & 87.50 hij \\
\hline B. bassiana, (BB-252) & $7.50 \mathrm{ab}$ & $25.00 \mathrm{~cd}$ & 85.00 hij & $10.00 \mathrm{ab}$ & 35.00 de & 80.00 hi \\
\hline Lecanicillium lecanii, (CS-625) & $7.50 \mathrm{ab}$ & 40.00 ef & $95.00 \mathrm{j}$ & $12.50 \mathrm{abc}$ & $55.00 \mathrm{~g}$ & $90.00 \mathrm{ij}$ \\
\hline L. lecanii, (V-4) & $5.00 \mathrm{ab}$ & 32.50 de & 80.00 hi & $5.00 \mathrm{ab}$ & 40.00 ef & $75.00 \mathrm{~h}$ \\
\hline Tween & $2.50 \mathrm{a}$ & $7.50 \mathrm{ab}$ & $15.00 \mathrm{abc}$ & $5.00 a b$ & $10.00 \mathrm{ab}$ & $17.50 \mathrm{bc}$ \\
\hline
\end{tabular}

Values are means of four replications

Means sharing common letters do not differ significantly $(P=0.05)$

and many other aphid species (Khan et al. 2012; Nazir et al. 2019). B. bassiana and L. lecanii were found to be the most virulent EPFs strains for controlling M. persicae with more than $80 \%$ mortality on the 10th day of treatment. A previous study by Hayden et al. (1992) reported that $B$. bassiana and $V$. lecanii caused maximum mortality of $S$. avenae after the ninth and eight day of treatment, respectively.

In previous studies, 12 strains of EPFs, viz. L. lecanii, P. farinosus, B. bassiana, M. anisopliae, C. scarabaeicola, and $N$. rileyi were screened for their effectiveness against $M$. persicae in which $B$. bassiana and L. lecanii were found to grow and control aphids in a broad range of temperature $\left(15-30^{\circ} \mathrm{C}\right)$ and humidity. The effective concentration of conidial suspension was also reported to be $1 \times 10^{7}$ conidia $/ \mathrm{ml}$, which corroborated the present findings (Yeo et al. 2003; Hong and Kim 2007). The results of the present study also showed that $L$. lecanii effectively controlled aphid when applied singly but had antagonistic effect when combined with $B$. bassiana. These findings are in conformity with those reported by Hall and Burges (1979) who claimed that V. lecanii can be used for the control of aphid populations but was not found effective when used in combination with other antagonists under the same laboratory conditions.

In all treatments, the mortality rate of $M$. persicae was found to be time dependent in cases of filtrate, conidial suspension, and even when used in combinations. The highest percent mortality was observed after 10 days, while after 3 days, the mortality was the minimum. Almost similar results were reported by Loureiro et al. (2004) who found an increase in mortality with the increase in time and concentration. Contrarily, Araujo et al. (2009) reported (90\%) mortality at the high concentration $\left(10^{7}\right.$ spore $\left./ \mathrm{ml}\right)$ of $B$. bassiana after 4.4 days. However, there might be differences in mortality rates due to difference in strains being evaluated, concentration, laboratory conditions, and material used.

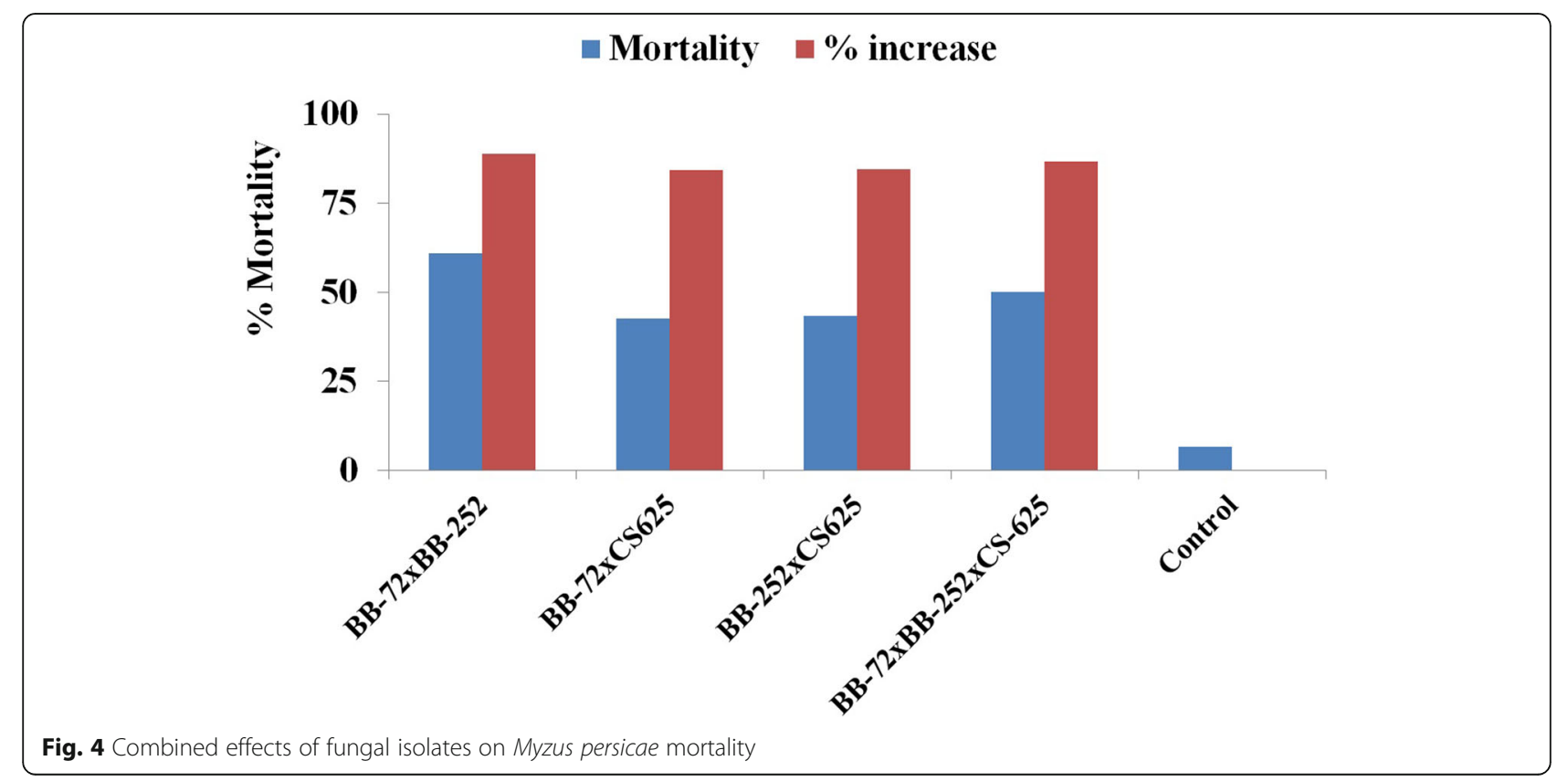


Table 3 Effect of combined treatments on the mortality of green peach aphid

\begin{tabular}{llll}
\hline Combined treatment of & \multicolumn{3}{l}{$\%$ mortality after } \\
\cline { 2 - 4 } fungal isolates & 3 days & 6 days & 10 days \\
\hline BB-72 + BB-252 & $15.0 \mathrm{~b}$ & $67.5 \mathrm{~d}$ & $100.0 \mathrm{e}$ \\
BB-72 + CS625 & $10.0 \mathrm{ab}$ & $42.5 \mathrm{C}$ & $75.0 \mathrm{~d}$ \\
BB-252 + CS625 & $7.5 \mathrm{ab}$ & $45.0 \mathrm{C}$ & $77.5 \mathrm{~d}$ \\
BB-72 + BB-252 + CS-625 & $12.5 \mathrm{ab}$ & $47.5 \mathrm{C}$ & $90.0 \mathrm{e}$ \\
Control (Tween) & $2.5 \mathrm{a}$ & $5.0 \mathrm{ab}$ & $12.5 \mathrm{ab}$ \\
\hline
\end{tabular}

Values are means of four replications

Means sharing common letters do not differ significantly $(P=0.05)$

\section{Conclusion}

The fungal strains, Beauveria bassiana, and Lecanicillium lecanii, used as filtrate and conidial suspensions, showed high mortality rates and can be effectively used for the control of green peach aphid. The effectiveness can be enhanced by combining different fungal strains.

\section{Abbreviations}

PDA: Potato dextrose agar; rpm: Revolutions per minute

\section{Authors' contributions}

All authors read and approved the final manuscript.

\section{Availability of data and materials}

Not applicable

\section{Ethics approval and consent to participate}

Not applicable

\section{Consent for publication}

Not applicable

\section{Competing interests}

The authors declare that they have no conflict of interest.

\section{Author details}

${ }^{1}$ The State Key Laboratory for Bio-Pesticides Engineering of Plant Disease Biocontrol and Insect Pests, Institute of Plant Protection, Chinese Academy of Agricultural Science, No. 12 Zhong-Guan-Cun South Street, Beijing 100081, China. ${ }^{2}$ Department of Entomology, Pir Mehr Ali Shah Arid Agriculture University, Rawalpindi, Pakistan. ${ }^{3}$ Department of Plant Pathology, Pir Mehr Ali Shah Arid Agriculture University, Rawalpindi, Pakistan.

Received: 7 August 2019 Accepted: 21 October 2019

Published online: 19 December 2019

\section{References}

Abbott WS (1925) A method of computing the effectiveness of an insecticide. J Econ Entomol 18:265-267

Ak K (2019) Efficacy of entomopathogenic fungi against the stored-grain pests, Sitophilus granarius L. and S. oryzae L. (Coleoptera: Curculionidae). Egypt J Biol. Pest Control 29:12

Amnuaykanjanasin A, Jirakkakul J, Panyasiri C, Panyarakkit P, Nounurai P, Chantasingh D, Eurwilaichitr L, Cheevadhanarak S, Tanticharoen M (2013) Infection and colonization of tissues of the aphid Myzus persicae and cassava mealybug Phenacoccus manihoti by the fungus Beauveria bassiana. BioControl 58:379-391

Araujo JM, Marques EJ, Oliveira JV (2009) Potencial de isolados de Metarhizium anisopliae e Beauveria bassiana e do óleo de Nim no controle do pulgão Lipaphis erysimi (Kalt.) (Hemiptera: Aphididae). Neotrop Entomol 38:520-525

Dhar S, Jindal V, Jariyal M, Gupta VK (2019) Molecular characterization of new isolates of the entomopathogenic fungus Beauveria bassiana and their efficacy against the tobacco caterpillar, Spodoptera litura (Fabricius) (Lepidoptera: Noctuidae). Egypt J Biol Pest Control 29:8

Dunne R, Donovan M (1977) Aphid control on tomatoes in a hydroponic system. Symposium on Production of Protected Crops in Peat and other Media, September 1977(82):137-140

El Husseini MM (2019a) Effect of the fungus, Beauveria bassiana (Balsamo) Vuillemin, on the beet armyworm, Spodoptera exigua (Hübner) larvae (Lepidoptera: Noctuidae), under laboratory and open field conditions. Egypt J Biol Pest Control 29:52

El Husseini MM (2019b) Efficacy of the fungus Beauveria bassiana (Balsamo) Vuillemin on the red palm weevil Rhynchophorus ferrugineus Olivier (Coleoptera: Curculionidae) larvae and adults under laboratory conditions. Egypt J Biol Pest Control 29:58

El Husseini MM (2019c) Efficacy of the entomopathogenic fungus, Metarhizium anisopliae (Metsch.), against larvae of the cotton leafworm, Spodoptera littoralis (Boisd.) (Lepidoptera: Noctuidae), under laboratory conditions. Egypt J Biol. Pest Control 29:50

Feng MG (1998) Diversity of entomopathogenic fungi as resources useful for microbial control of insect pests. Proceedings of the First International Symposium on the Geoenvironmental Changes and Biodiversity in the Northeast Asia, Seoul, Korea, 16-19 November, 1998, 387-392.

Freed S, Jin F.-L, Ren S.-X (2011) Phylogenetics of entomopathogenic fungi isolated from the soils of different ecosystems. Pakistan J Zool 43:417-425

Hall RE, Burges HD (1979) Control of aphids in glasshouses with the fungus, Verticillium lecanii. Ann Appl Biol 93(3):235-246

Hayden TP, Bidochka MJ, Khachatourians GG (1992) Entomopathogenicity of several fungi toward the English grain aphid (Homoptera: Aphididae) and enhancement of virulence with host passage of Paecilomyces farinosus. J Econ Entomol 85(1):58-64

Hong SI, Kim K (2007) Selection of entomopathogenic fungi for aphid control. J Biosci Bioeng 104(6):498-505

Hywell-Jones NL, Gillespie AT (1990) Effect of temperature on spore germination in Metarhizium anisopliae and Beauveria bassiana. Mycol Res 94:389-392

Javed K, Javed H, Mukhtar T, Qiu D (2019) Efficacy of Beauveria bassiana and Verticillium lecanii for the management of whitefly and aphid. Pak J Agri Sci 56(3):669-674

Khan S, Lihua G, HuaiXing S, Mahmut M, Dewen Q (2012) Bioassay and enzymatic comparison of six entomopathogenic fungal isolates for virulence or toxicity against green peach aphids Myzus persicae. Afr J Biotechnol 11(77):14193-14203

Loureiro ES, Oliveira NC, Wilcken CF, Batista AB (2004) Patogenicidade de Verticillium lecanii ao pulgão-do-pinus. Rev Árvore 28:765-770

Mohamed GS (2019) The virulence of the entomopathogenic fungi on the predatory species, Cryptolaemus montrouzieri Mulsant (Coleoptera: Coccinellidae) under laboratory conditions. Egypt J Biol Pest Control 29:42

Nazir T, Basit A, Hanan A, Majeed M, Qiu D (2019) In vitro Pathogenicity of some entomopathogenic fungal strains against green peach aphid Myzus persicae (Homoptera: Aphididae). Agronomy 9(1):7

Nielsen C, Wraight SP (2009) Exotic aphid control with pathogens. In: Use of microbes for control and eradication of invasive arthropods. Springer, Dordrecht, pp 93-113

Rousselin A, Bevacqua D, Sauge MH, Lescourret F, Mody K, Jordan MO (2017) Harnessing the aphid life cycle to reduce insecticide reliance in apple and peach orchards. A review. Agron Sus Develop 37(5):38

Sain SK, Monga D, Kumar R, Nagrale DT, Kranthi S, Kranthi KR (2019) Comparative effectiveness of bioassay methods in identifying the most virulent entomopathogenic fungal strains to control Bemisia tabaci (Gennadius) (Hemiptera: Aleyrodidae). Egypt J Biol Pest Control 29:31

Sayed SM, Ali EF, Al-Otaibi SS (2019) Efficacy of indigenous entomopathogenic fungus, Beauveria bassiana (Balsamo) Vuillemin, isolates against the rose aphid, Macrosiphum rosae L. (Hemiptera: Aphididae) in rose production. Egypt J Biol Pest Control 29:19

Shah PA, Goettel MS (1999) Directory of Microbial Control Products, Society for Invertebrate Pathology, Division of Microbial Control, http://www. sipweb. org/directory.htm.

Singh V, Mawar R, Lodha S (2012) Combined effects of biocontrol agents and soil amendments on soil microbial populations, plant growth and incidence of charcoal rot of cowpea and wilt of cumin. Phytopathol Mediterr 51:307-316

Tang QL, Ma KS, Hou YM, Gao XW (2017) Monitoring insecticide resistance and diagnostics of resistance mechanisms in the green peach aphid, Myzus persicae (Sulzer) (Hemiptera: Aphididae) in China. Pest Biochem Physiol 143: $39-47$ 
Tuncer C, Kushiyev R, Erper I, Ozdemir IO, Saruhan I (2019) Efficacy of native isolates of Metarhizium anisopliae and Beauveria bassiana against the invasive ambrosia beetle, Xylosandrus germanus Blandford (Coleoptera: Curculionidae: Scolytinae). Egypt J Biol Pest Control 29:28

Xu J-H, Feng M-G (2002) Pandora delphacis (Entomophthorales: Entomophthoraceae) infection affects the fecundity and population dynamics of Myzus persicae (Homoptera: Aphididae) at varying regimes of temperature and relative humidity in the laboratory. Biol Control 25:85-91

Yeo H, Pell JK, Alderson PG, Clark SJ, Pye BJ (2003) Laboratory evaluation of temperature effects on the germination and growth of entomopathogenic fungi and on their pathogenicity to two aphid species. Pest Manage Sci 59(2):156-165

Yun HG, Kim DJ, Gwak WS, Shin TY, Woo SD (2017) Entomopathogenic fungi as dual control agents against both the pest Myzus persicae and phytopathogen Botrytis cinerea. Mycobiology 45:192-198

\section{Publisher's Note}

Springer Nature remains neutral with regard to jurisdictional claims in published maps and institutional affiliations.

\section{Submit your manuscript to a SpringerOpen ${ }^{\circ}$ journal and benefit from:}

- Convenient online submission

- Rigorous peer review

- Open access: articles freely available online

- High visibility within the field

- Retaining the copyright to your article

Submit your next manuscript at $\boldsymbol{\wedge}$ springeropen.com 